\title{
Thoracotomy and VATS Surgery in Local Non-Small-Cell Lung Cancer: Differences in Long-Term Health-Related Quality Of Life
}

\author{
Ville Rauma, ${ }^{1}$ Saana Andersson, ${ }^{1}$ Eric M. Robinson, ${ }^{2}$ Jari V. Räsänen, ${ }^{1}$ \\ Harri Sintonen, ${ }^{3}$ Jarmo A. Salo, ${ }^{1}$ Ilkka K. Ilonen ${ }^{1}$
}

\begin{abstract}
Very long-term health-related quality of life (HRQoL) is an important end point in operated early stage non -small-cell lung cancer with good prognosis. The results for very long-term HRQoL after minimally invasive video-assisted thoracoscopic surgery (VATS) has not been evaluated and compared to thoracotomy. Surprisingly, inferior overall HRQoL was evident for patients operated with VATS, independent of preoperative factors including age, comorbidities, and pulmonary function tests.

Background: As a result of routine low-dose computed tomographic screening, lung cancer is more frequently diagnosed at earlier, operable stages of disease. In treating local non-small-cell lung cancer, video-assisted thoracoscopic surgery (VATS), a minimally invasive surgical approach, has replaced thoracotomy as the standard of care. While short-term quality-of-life outcomes favor the use of VATS, the impact of VATS on long-term health-related quality of life (HRQLL) is unknown. Patients and Methods: We studied patients who underwent lobectomy for the treatment of non-small-cell lung cancer from January 2006 to January 2013 at a single institution $(n=456)$. Patients who underwent segmentectomy $(n=27)$, who received neoadjuvant therapy $(n=13)$, or who were found to have clinical stage $>$ T2 or $>$ N0 disease $(n=45)$ were excluded from analysis. At time of HRQoL assessment, 199 patients were eligible for study and were mailed the generic HRQoL instrument 15D. Results: A total of 180 patients (90.5\%) replied; 92 respondents underwent VATS while 88 underwent open thoracotomy. The VATS group more often had adenocarcinoma $(P=.006)$, and lymph node stations were sampled to a lesser extent $(P=.004)$; additionally, hospital length of stay was shorter among patients undergoing VATS $(P=.001)$. No other clinical or pathologic differences were observed between the 2 groups. Surprisingly, patients who underwent VATS scored significantly lower on $\mathrm{HRQoL}$ on the dimensions of breathing, speaking, usual activities, mental function, and vitality, and they reported a lower total 15D score, which reflects overall quality of life $(P<.05)$. Conclusion: In contrast to earlier short-term reports, long-term quality-of-life measures are worse among patients who underwent VATS compared to thoracotomy.
\end{abstract}

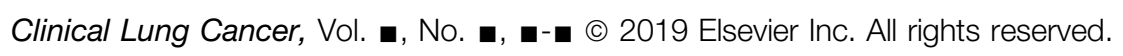

Keywords: 15D, NSCLC

\section{Introduction}

Lung cancer is the leading cause of cancer death globally and is among the leading cancers in overall total incidence. ${ }^{1}$ In Finland, lung cancer is the leading cause of cancer-related death; 5-yearsurvival rates reach only $10 \%$ to $15 \% .{ }^{2}$ Despite these dismal figures,

${ }^{1}$ Department of General Thoracic and Esophageal Surgery, Heart and Lung Center, Helsinki University Central Hospital, Helsinki, Finland

${ }^{2}$ Icahn School of Medicine at Mount Sinai, New York, NY

${ }^{3}$ Department of Public Health, Helsinki University, Faculty of Medicine, Helsinki, Finland new paradigms in screening and diagnosis are expected to shift a significant proportion of the lung cancer burden from advanced metastatic disease to earlier, treatable local disease. Low-dose computed tomographic screening, for example, has been prospectively shown to reduce mortality from lung cancer compared to

Submitted: Feb 19, 2018; Revised: Jan 16, 2019; Accepted: May 6, 2019

Address for correspondence: Ilkka K. Ilonen, MD, PhD, Heart and Lung Center, Department of General Thoracic and Esophageal Surgery, Helsinki University Central Hospital, Haartmaninkatu 4, PO Box 340, 00290 Helsinki, Finland E-mail contact: ilkka.ilonen@helsinki.fi 


\section{Thoracotomy and VATS}

single-view chest radiography. ${ }^{3}$ For patients diagnosed with early stage operable disease, 5-year survival rates may exceed $50 \%{ }^{1}$ Additionally, with promising chemo- and radiotherapy strategies and modern surgical interventions, the life expectancy of lung cancer patients is further improving. ${ }^{2}$

In addition to improvements in prognosis or the quantity of remaining life years, the quality of remaining life years is increasingly viewed as an essential component in devising novel strategies for the treatment of cancer. ${ }^{4}$ As a general trend in the field of surgery, minimally invasive methods are favored whenever suitable. Since its introduction in the 1990s, video-assisted thoracoscopic surgery (VATS) has gained a strong foothold. ${ }^{5}$ It provides oncologic efficacy similar to open thoracotomy, ${ }^{6,7}$ and even better perioperative survival. $^{8}$ VATS patients encounter fewer perioperative complications ${ }^{8,9}$ and experience less postoperative pain. ${ }^{10}$ Thus, patients with already deteriorated health reserves-such as patients with poor preoperative lung functions ${ }^{11,12}$ and those with additional comorbidities $^{8}$ - seem to benefit from VATS. In consideration of the abovementioned advantages and the lower overall cost, ${ }^{13}$ VATS is now largely considered the standard of care in the surgical treatment of local non-small-cell lung cancer (NSCLC). ${ }^{5}$

While numerous studies have associated VATS with better shortterm postoperative health-related quality of life (HRQoL), ${ }^{10,14,15}$ studies evaluating long-term HRQoL differences are scarce, and to date only a few studies have evaluated the effect of surgical treatment on HRQoL over a time period more than 2 years. ${ }^{16}$

To examine this matter, we assessed the long-term HRQoL minimum 2 years after the operation among patients who underwent surgery for local NSCLC in our clinic between the years 2006 and 2013.

\section{Patients and Methods Patients}

We studied patients who underwent lobectomy for the treatment of NSCLC from January 2006 to January 2013 at a single institution $(n=456)$. Figure 1 summarizes the patient selection. Patients who underwent surgery from January 2006 to June 2009 received the HRQoL instrument in July $2011(\mathrm{n}=199)$, while patients who underwent surgery between July 2009 and January $2013(\mathrm{n}=257)$ received their HRQoL instrument in May 2016. A national registry provided information concerning mortality. At the time of the HRQoL assessment, 79 patients from the first group and 93 patients from the second group had died. Thirteen patients who received neoadjuvant therapy and 45 patients with advanced disease (clinical stage $\geq \mathrm{T} 3$ or $\geq \mathrm{N} 1$ ) were also ineligible. Twentyseven patients who had undergone sublobar resection were further excluded. In total, 199 patients were included in this study and sent the $15 \mathrm{D}^{17}$ HRQoL instrument by mail. After 2 months, nonrespondents were contacted by phone and asked to either return the survey by mail or answer it over the phone.

Disease was staged according to the 7th edition of the American Joint Committee on Cancer tumor, node, metastasis classification system..$^{18}$ The Charlson comorbidity index $(\mathrm{CCI})^{19}$ was applied to assess the extent of comorbidities from the medical records.

\section{Surgical Techniques}

Thoracotomy was performed through the muscle-sparing anterolateral approach, and patients were scheduled for epidural pain catheter preoperatively. The success rate of the epidural anesthesia was not systematically recorded into electronic patient records.

VATS was introduced in our clinic in 2006 and was performed almost uniformly through the 3-port approach. ${ }^{20}$ Local anesthetic was applied before the incision was made. Additional ports were placed at the discretion of the operating surgeon. All patients postoperatively had a $28-\mathrm{F}$ pleural catheter on active suction placed, and all had access to specialized pain management service.

The decision between VATS or thoracotomy as the surgical method was partially surgeon dependent and partially influenced by many other factors, eg, the designated operating room, the gradual implementation of VATS in our clinic, and the educational requirements of the clinic's residents. Surgeons did not have their own patients, as the patients came from a single queue and were operated in order. The universal health care system in Finland prevents socioeconomic selection bias, as surgeons do not get paid on the basis of the type of operations they perform, and patient fees do not differ between the methods either.

\section{Quality-of-Life Instrument}

The 15D is a self-administered generic quality-of-life instrument with 15 dimensions and a single index score, the 15D score, representing the overall quality of life. Each dimension has 5 ordinal levels, from which the final dimension level values and the 15D score can be calculated using a set of population-based preference or utility weights. Each dimension level value and the $15 \mathrm{D}$ score ranges from 0 to 1 , with a high score representing a good state of function and quality of life. A minimal important difference in the $15 \mathrm{D}$ score is $0.015 .{ }^{21}$

\section{Statistical Analysis}

SPSS 22.0.0.0 software (IBM, Armonk, NY) was used to perform statistical analysis. Results for continuous variables are provided as mean (standard deviation) and for categorical variables as $\mathrm{n}$ (percentage). Independent sample $t$ test served to compare parametric and Mann-Whitney $U$ test nonparametric continuous variables, while the chi-square test was used to compare categorical variables. Two-tailed $P<.05$ was considered significant.

The Helsinki University hospital ethics committee approved the study.

\section{Results}

\section{Study Population}

A total of 180 patients (90.5\%) responded to the questionnaire (71 of the earlier cohort and 109 of the later cohort). The groups were combined for analysis. Of the respondents, $92(51.1 \%)$ underwent VATS and 88 (48.9\%) underwent thoracotomy. There were 4 conversions (4.0\%); those patients were included in the thoracotomy group for the analysis. The VATS group had a higher response rate $(94.8 \%)$ than the thoracotomy group $(86.3 \%)(P=$ $.040)$. Table 1 summarizes preoperative patient demographics. Table 2 describes peri- and postoperative patient and operational characteristics. The overall mean and median ages for the respondents were 65.81 (8.39) and 67 years, respectively. Adenocarcinoma was more common in the VATS group $(81.5 \%$ vs. $59.1 \% ; P=.006)$, and they had on average fewer lymph node stations sampled during the operation $(P=.004)$. Patients undergoing VATS were also discharged earlier with a shorter mean 


\section{Figure 1 Patient Flowchart}

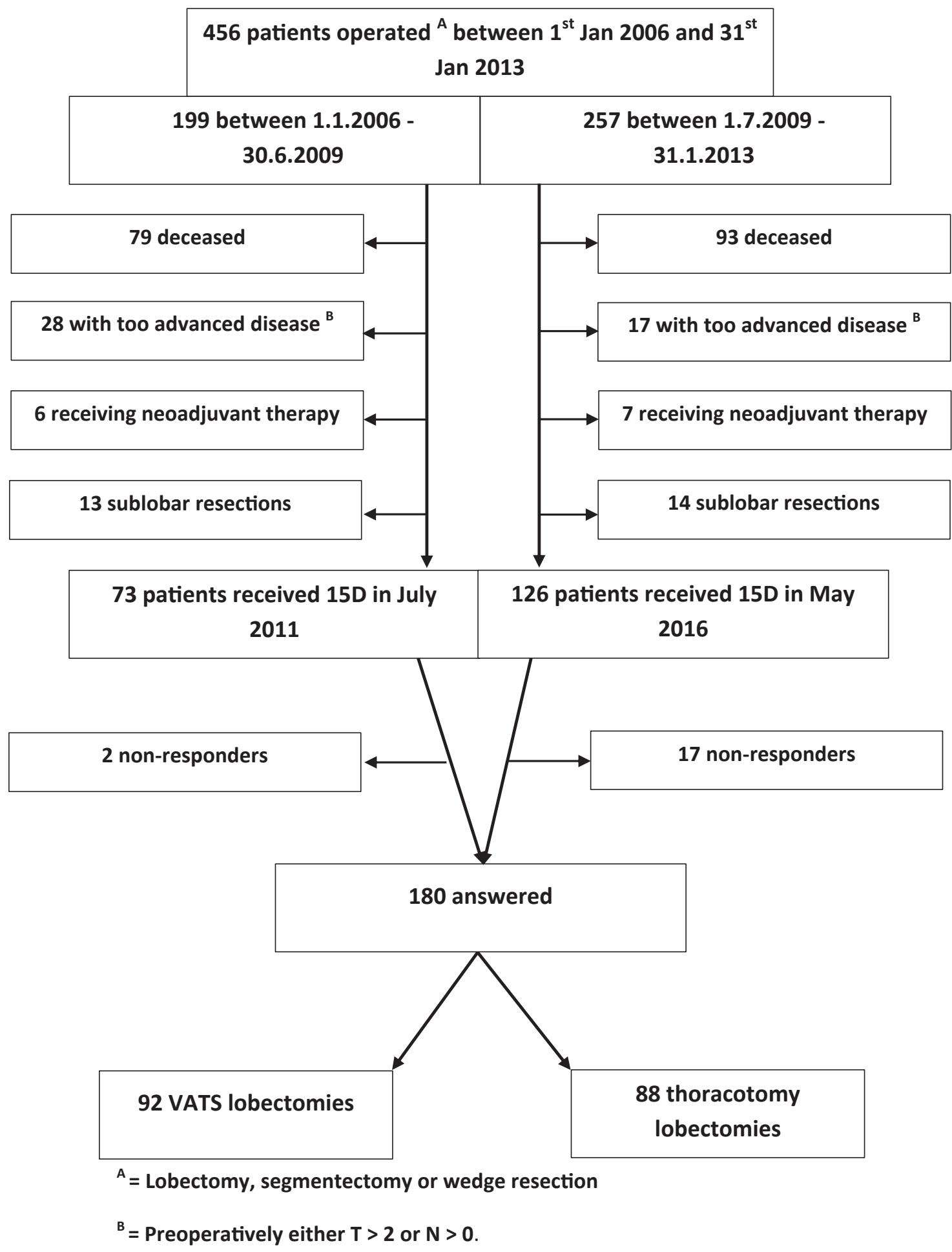

hospital length of stay of 6.4 (4.6) days versus 8.7 (5.2) days for the thoracotomy group $(P=.001)$. The median hospital length of stay was likewise shorter in the VATS group (5 days vs. 7 days). No differences in follow-up time, age, sex distribution, CCI, percentage of forced expiratory volume in 1 second $\left(\mathrm{FEV}_{1} \%\right)$, percentage of diffusing capacity of the lungs for carbon monoxide (DLCO\%), smoking status, clinical or pathologic stage, tumor location, adjuvant therapy, or complication rate were observed between the 2 


\section{Thoracotomy and VATS}

\begin{tabular}{|c|c|c|c|}
\hline Characteristic & $\begin{array}{c}\text { VATS } \\
(\mathrm{N}=92)\end{array}$ & $\begin{array}{l}\text { Thoracotomy } \\
(\mathrm{N}=88)\end{array}$ & $\boldsymbol{P}$ \\
\hline Age $(\mathrm{y})$, mean $(\mathrm{SD})$ & $66.9(8.1)$ & $64.7(8.5)$ & NS \\
\hline Women & $42(45.7)$ & $51(58.0)$ & NS \\
\hline CCI & & & NS \\
\hline 0 & $33(35.9)$ & $43(48.9)$ & \\
\hline 1 & $30(32.6)$ & $23(26.1)$ & \\
\hline 2 & $20(21.7)$ & $12(13.6)$ & \\
\hline 3 & $7(7.6)$ & $7(8.0)$ & \\
\hline 4 & $1(1.1)$ & $1(1.1)$ & \\
\hline$\geq 5$ & $1(1.1)$ & $2(2.3)$ & \\
\hline $\mathrm{FEV}_{1} \%,{ }^{\mathrm{a}}$ mean $(\mathrm{SD})$ & 79.0 (19.7) & 79.4 (18.2) & NS \\
\hline DLCO $\%,{ }^{b}$ mean (SD) & $76.4(17.6)$ & $77.5(16.8)$ & NS \\
\hline Smoking Status & & & NS \\
\hline Smoker & 73 (79.3) & $73(83.0)$ & \\
\hline Current smoker ${ }^{c}$ & $45(48.9)$ & $37(42.0)$ & \\
\hline Never smoker & $19(20.7)$ & $15(17.0)$ & \\
\hline $\begin{array}{l}\text { Smoking pack-years, }{ }^{d} \\
\text { mean (SD) }\end{array}$ & $40.2(23.0)$ & $33.9(21.5)$ & NS \\
\hline Clinical Stage & & & NS \\
\hline $\mid A$ & $68(73.9)$ & $56(63.6)$ & \\
\hline IB & 18 (19.6) & $23(26.1)$ & \\
\hline$\| \mathrm{A}$ & $6(6.5)$ & $9(10.2)$ & \\
\hline
\end{tabular}

Data are presented as $\mathrm{n}(\%)$ unless otherwise indicated.

Abbreviations: $\mathrm{CCl}=$ charlson comorbidity index; $\mathrm{DLCO} \%=$ percentage of diffusing capacity of lungs for carbon monoxide; $\mathrm{FEV}_{1} \%=$ percentage of forced expiratory volume in 1 second NS = not significant; SD = standard deviation; VATS = video-assisted thoracoscopic surgery 'Patients' $\mathrm{FEV}_{1} \%$ value compared to predicted value.

'Patients' DLCO\% value compared to predicted value.

${ }^{\mathrm{c}}$ At time of operation.

${ }^{\mathrm{d} A m o n g}$ smokers.

groups. No difference was observed between the groups in the presence of no to low comorbidity (CCI 0-1) and high comorbidity $(\mathrm{CCI} \geq 2)(P=.332)$.

\section{Quality of Life}

Figure 2 summarizes the HRQoL scores of the 2 groups. No differences were identified on the dimensions of mobility, vision, hearing, sleeping, eating, excretion, discomfort and symptoms, depression, distress, and sexual activity $(P>.05)$. The VATS group scored both statistically and clinically significantly lower on the dimensions of breathing (0.637 vs. $0.719, P=.030)$, speaking (0.942 vs. $0.973, P=.046)$, usual activities (0.746 vs. $0.821, P=$ $.030)$, mental function ( 0.818 vs. $0.917, P=.001)$, vitality $(0.767$ vs. $0.824, P=.049)$, and in the total $15 \mathrm{D}$ score $(0.809$ vs. 0.851 , $P=.028)$.

\section{Discussion}

In a retrospective study of 199 patients who underwent lobectomy for surgical resection of early stage NSCLC, we report lower long-term HRQoL in patients undergoing resection by VATS versus thoracotomy. These results are in conflict with previous short-term findings ${ }^{10,14,15}$ and with 2 previous long-term studies, which also suggest HRQoL differences favoring VATS. ${ }^{22,23}$
Table 2 Peri- and Postoperative Patient and Operation Characteristics

\begin{tabular}{|c|c|c|c|}
\hline Characteristic & $\begin{array}{c}\text { VATS } \\
(N=92)\end{array}$ & $\begin{array}{c}\text { Thoracotomy } \\
(\mathrm{N}=\mathbf{8 8})\end{array}$ & $P$ \\
\hline Tumor Location & & & NS \\
\hline Right superior & $40(43.5)$ & $22(25.0)$ & \\
\hline Right inferior & $20(21.7)$ & $30(34.1)$ & \\
\hline Right medial & $3(3.3)$ & $4(4.5)$ & \\
\hline Left superior & $16(17.4)$ & $18(20.5)$ & \\
\hline Left inferior & $13(14.1)$ & $14(15.9)$ & \\
\hline Histology & & & .006 \\
\hline Adenocarcinoma $^{a}$ & $75(81.5)$ & $52(59.1)$ & \\
\hline Squamous-cell carcinoma & $16(17.4)$ & $32(36.4)$ & \\
\hline Large-cell carcinoma & $1(1.1)$ & $1(1.1)$ & \\
\hline Other & 0 & $3(3.4)$ & \\
\hline Pathologic Stage & & & NS \\
\hline IA & $60(65.2)$ & $53(60.2)$ & \\
\hline IB & $15(16.3)$ & $15(17.0)$ & \\
\hline$\| \mathrm{A}$ & $11(12.0)$ & $13(14.8)$ & \\
\hline$\| \mathrm{B}$ & $2(2.2)$ & $2(2.3)$ & \\
\hline IIIA & $4(4.3)$ & $5(5.7)$ & \\
\hline $\begin{array}{l}\text { No. of nodal stations } \\
\text { sampled, mean (SD) }\end{array}$ & $3.5(1.8)$ & $4.5(1.6)$ & .004 \\
\hline Adjuvant therapy ${ }^{\mathrm{b}}$ & $6(6.5)$ & $9(10.2)$ & NS \\
\hline Hospital stay (d) & $6.4(4.6)$ & $8.7(5.2)$ & .001 \\
\hline Complication & $18(19.6)$ & 17 (19.3) & NS \\
\hline Progression & $8(8.7)$ & $8(9.1)$ & NS \\
\hline Follow-up (mo), mean (SD) & $50.1(14.7)$ & 50.7 (11.4) & NS \\
\hline
\end{tabular}

Data are presented as $n(\%)$ unless otherwise indicated.

Abbreviations: NS = not significant; SD = standard deviation; VATS = video-assisted thoracoscopic surgery.

alncluding bronchioloalveolar carcinomas.

${ }^{\mathrm{b}}$ Chemotherapy or radiotherapy.

However, these latter studies of long-term HRQoL included only 51 and 33 patients. Nevertheless, our results are particularly striking, as one of the largest differences was observed on the dimension of breathing, which directly contrast with previous studies emphasizing the positive effects of VATS on pulmonary function ${ }^{24}$ and in patients with already decreased pulmonary function. ${ }^{11}$

Baseline differences in pulmonary function do not appear to account for the observed HRQoL differences. The groups did not differ preoperatively on $\mathrm{FEV}_{1} \%(P=.826)$ or on $\mathrm{DLCO} \%(P=$ .658), suggesting differences resulting from the treatment. However, previous studies have failed to consistently link pulmonary function tests and subjective HRQoL. ${ }^{25}$ One study demonstrated a marginal correlation between the preoperative percentage predicted transfer factor of the lung for carbon monoxide $\left(\mathrm{TL}_{\mathrm{CO}}\right)$ value and the 6month postoperative global health status, ${ }^{26}$ while another study found no correlation at all between the pulmonary function tests and HRQoL. ${ }^{27}$ Thus, the relationship between baseline pulmonary function tests and HRQoL differences remains unclear.

Another potential explanation is the distribution of comorbidities between patient groups. Comorbidities seem to have a negative relationship with postoperative HRQoL, especially when the patient has more than one comorbid condition. ${ }^{16}$ However, as shown in 


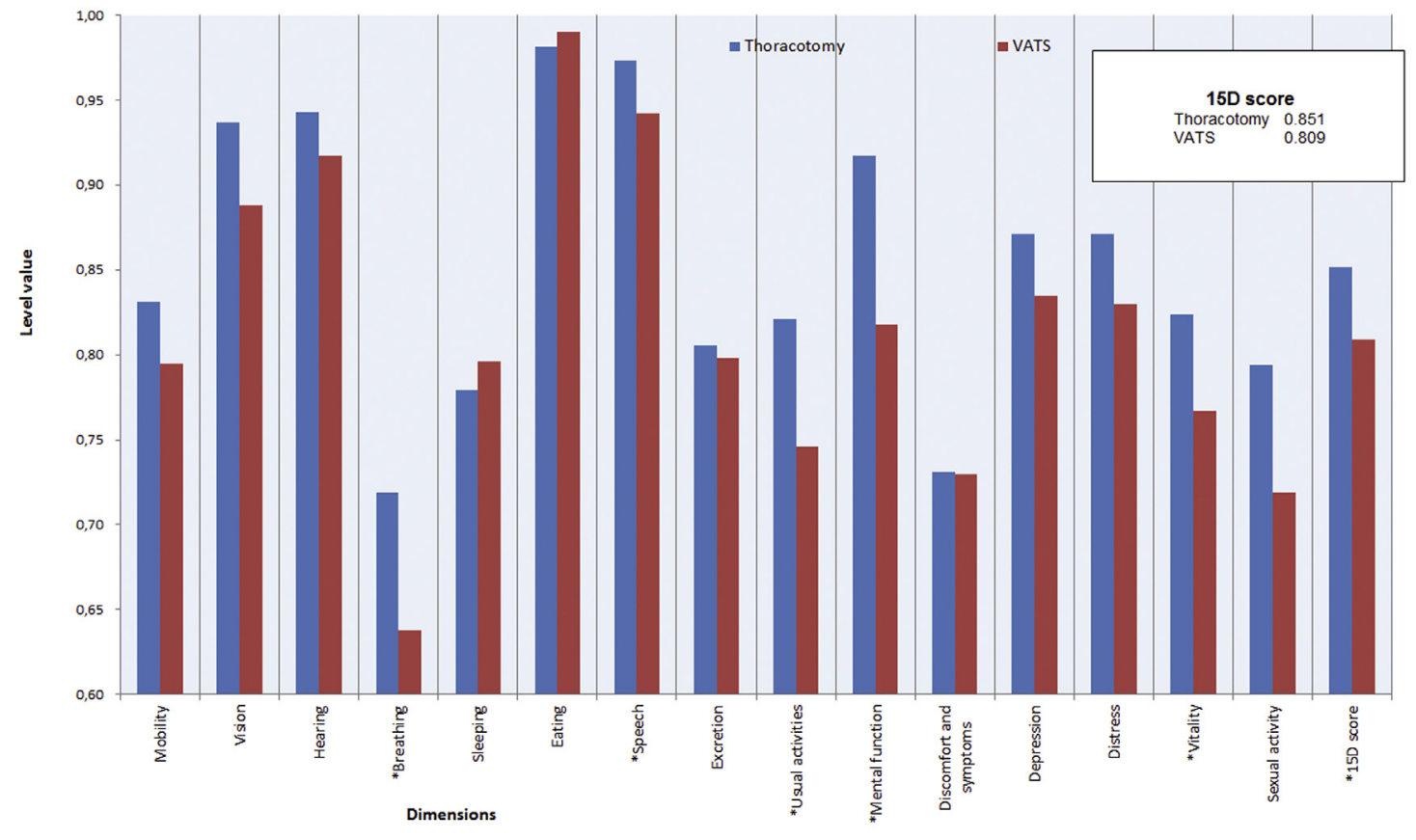

Table 1, the patient groups did not differ in preoperative CCI distribution. As our clinical impression was that patients with poorer health reservoirs were more likely to undergo VATS, we found this result surprising. Originally CCI was developed to predict mortality, not HRQoL, ${ }^{19}$ and a study comparing 3 different multimorbidity assessment instruments found CCI to have the weakest explanatory power concerning HRQoL. ${ }^{28}$ Despite this, another study of prostate cancer patients demonstrated a significant, yet relatively weak, association between CCI and long-term HRQoL. ${ }^{29}$ A third study demonstrated a significant association between self-reported CCI and HRQoL, while CCI derived directly from medical records failed to predict HRQoL. ${ }^{30}$ This makes sense because patients are probably more likely to report diseases that disturb their HRQoL.

Another potential explanation is the older age or mental age of the patients who underwent VATS. While the age difference between the 2 groups did not reach statistical significance $(P=.074)$, a more comprehensive index of the impact of aging and on mental age, such as a frailty index, might account for observations of worse HRQoL in the VATS groups. Frailty, assessed by multidimensional models, is a comprehensive concept for the evaluation of eligibility for surgery, and it seems to have a strong predictive value at least on survival. ${ }^{31}$ Of note, the greatest difference between the 2 groups was on the dimension of mental function (0.818 vs. $0.917, P=.001)$. This observation may reflect underlying baseline differences in frailty that we failed to capture, and that could explain differences in HRQoL despite similar individual objective preoperative measurements.

Differences in baseline clinical and pathologic characteristics were observed for some features between the 2 groups. Adenocarcinoma was significantly more common among VATS patients, while the thoracotomy group had 2 times as many squamous-cell carcinomas. Because squamous-cell carcinoma tends to have more often central, and adenocarcinoma peripheral, lesions, ${ }^{1,32}$ this may bias the results in some way-although the relationship with quality-of-life measures is not obvious. The possible effect that the observed difference in the number of lymph node stations sampled could have on HRQoL remains unclear, while oncologically there was no difference in the staging or disease progression between the groups.

Finally, another explanation for the observed differences in HRQoL is differences in preoperative counseling between the groups. While thoracotomy patients are told to expect postoperative pain and at least early deterioration of their daily performance status, VATS patients may be given a more positive impression concerning the effects of the surgery on their HRQoL. This association between the fulfillment of patient expectations and HRQoL gains has been previously reported, for example, in total joint replacement surgery. Patients with lower procedural expectations were more likely to have their expectations fulfilled and to report greater gains in HRQoL. ${ }^{33}$ This is also consistent with previous observations of persistent pain after lung cancer surgery. One long-term report found a slight reduction in baseline pain favoring VATS but no difference between VATS and thoracotomy when considering the impact of pain on daily activities. ${ }^{34}$ This latter negative result suggests that patient assessments of quality of life are nested within additional factors such as expectations of procedure benefit and risk.

Our study has some limitations. The retrospective design and lack of baseline data on HRQoL precluded identification of actual changes in HRQoL as a consequence of the surgical method chosen, enabling only the comparison of HRQoL values at a single time 


\section{Thoracotomy and VATS}

point. Baseline HRQoL information would be particularly useful for clarifying the potential impact of patient procedural expectations as well as baseline differences in mental function or frailty between the 2 groups. The 2-part collection of data may also predispose the results to some temporal bias. Notably, the latter cohort had significantly longer interim follow-up period before HRQoL assessment (mean 55.8 vs. 42.4 months, $P=.001$ ). Nevertheless, both cohorts had a similar percentage of VATS patients $(48.4 \%$ vs. 49.3\%), and HRQoL results were consistent across the 2 collection periods - though some differences were only trending as a result of smaller sample sizes.

The strengths of this study include the cohort size and response rate. To our knowledge, this is the largest study of long-term HRQoL outcomes in patients who underwent VATS versus thoracotomy for early stage resection. Moreover, our response rate exceeded $90 \%$, suggesting that our sample is highly representative.

\section{Conclusion}

We report the surprising result that patients undergoing VATS had worse long-term HRQoL scores in several critical dimensions, including breathing and overall 15D score. Further investigation is necessary to clarify this unexpected result.

\section{Clinical Practice Points}

- Both thoracotomy and minimally invasive VATS approach for early stage NSCLC are associated with decreased HRQoL in dimensions dependent on physical activity.

- Pulmonary function tests are poor surrogates for predicting postoperative HRQoL, and they should be used only in perspective for predicting morbidity and mortality.

- For reasons not fully understood, patients operated with VATS have inferior HRQoL. More studies are needed to assess the causes for this finding, as this finding was unrelated to conventional estimates of operability including: performance status, patient age, CCI, or pulmonary function tests.

\section{Acknowledgments}

This work was supported by the Foundation of the Finnish AntiTuberculosis Association and by the Foundation of Väinö and Laina Kivi. The authors thank Yvonne Sundström (Department of General Thoracic and Esophageal Surgery, Heart and Lung Center, Helsinki University Central Hospital, Helsinki, Finland) for secretarial assistance.

\section{Disclosure}

The authors have stated that they have no conflict of interest.

\section{References}

1. Brambilla E, Travis WD. Lung cancer. In: Stewart BW, Wild CP, eds. World Cancer Report, 2014. Lyon, France: International Agency for Research on Cancer; 2014:350-61.

2. Finnish Cancer Registry, Available at: https://cancerregistry.fi/statistics/cancerstatistics/. Accessed: January 12, 2018.

3. National Lung Screening Trial Research Team, Aberle DR, Adams AM, et al Reduced lung-cancer mortality with low-dose computed tomographic screening N Engl J Med 2011; 365:395-409.

4. Rummans TA, Bostwick JM, Clark MM, Mayo Clinic Cancer Center Quality of Life Working Group. Maintaining quality of life at the end of life. Mayo Clin Proc 2000; 75:1305-10.
5. Vannucci F, Gonzalez-Rivas D. Is VATS lobectomy standard of care for operable non-small cell lung cancer? Lung Cancer 2016; 100:114-9.

6. Berry MF, D'Amico TA, Onaitis MW, Kelsey CR. Thoracoscopic approach to lobectomy for lung cancer does not compromise oncologic efficacy. Ann Thorac Surg 2014; 98:197-202.

7. Licht PB, Jorgensen OD, Ladegaard L, Jakobsen E. A national study of nodal upstaging after thoracoscopic versus open lobectomy for clinical stage I lung cancer. Ann Thorac Surg 2013; 96:943-9.

8. Falcoz PE, Puyraveau M, Thomas PA, et al. Video-assisted thoracoscopic surgery versus open lobectomy for primary non-small-cell lung cancer: a propensitymatched analysis of outcome from the European Society of Thoracic Surgeon database. Eur I Cardiothorac Surg 2016; 49:602-9.

9. Nwogu CE, D’Cunha J, Pang H, et al. VATS lobectomy has better perioperative outcomes than open lobectomy: CALGB 31001, an ancillary analysis of CALGB 140202 (Alliance). Ann Thorac Surg 2015; 99:399-405.

10. Bendixen M, Jorgensen OD, Kronborg C, Andersen C, Licht PB. Postoperative pain and quality of life after lobectomy via video-assisted thoracoscopic surgery or anterolateral thoracotomy for early stage lung cancer: a randomised controlled trial. Lancet Oncol 2016; 17:836-44.

11. Oparka J, Yan TD, Ryan E, Dunning J. Does video-assisted thoracic surgery provide a safe alternative to conventional techniques in patients with limited pulmonary function who are otherwise suitable for lung resection? Interact Cardiovasc Thorac Surg 2013; 17:159-62.

12. Ceppa DP, Kosinski AS, Berry MF, et al. Thoracoscopic lobectomy has increasing benefit in patients with poor pulmonary function: a Society of Thoracic Surgeons Database analysis. Ann Surg 2012; 256:487-93.

13. Swanson SJ, Meyers BF, Gunnarsson CL, et al. Video-assisted thoracoscopic lobectomy is less costly and morbid than open lobectomy: a retrospective multiinstitutional database analysis. Ann Thorac Surg 2012; 93:1027-32.

14. Balduyck B, Hendriks J, Lauwers P, Van Schil P. Quality of life evolution after lung cancer surgery: a prospective study in 100 patients. Lung Cancer 2007; 56 423-31.

15. Handy JR Jr, Asaph JW, Douville EC, Ott GY, Grunkemeier GL, Wu Y. Does video-assisted thoracoscopic lobectomy for lung cancer provide improved functional outcomes compared with open lobectomy? Eur J Cardiothorac Surg 2010; $37: 451-5$.

16. Poghosyan H, Sheldon LK, Leveille SG, Cooley ME. Health-related quality of life after surgical treatment in patients with non-small cell lung cancer: a systematic review. Lung Cancer 2013; 81:11-26.

17. Sintonen H. The $15 \mathrm{D}$ instrument of health-related quality of life: properties and applications. Ann Med 2001; 33:328-36.

18. Mirsadraee S, Oswal D, Alizadeh Y, Caulo A, van Beek EJ. The 7th lung cancer TNM classification and staging system: review of the changes and implications. World J Radiol 2012; 4:128-34.

19. Charlson ME, Pompei P, Ales KL, MacKenzie CR. A new method of classifying prognostic comorbidity in longitudinal studies: development and validation. J Chronic Dis 1987; 40:373-83.

20. Hansen HJ, Petersen RH. A video-atlas of video-assisted thoracoscopic lobectomy using a standardized three-port anterior approach. Ann Cardiothorac Surg 2012; 1:104.

21. Alanne S, Roine RP, Räsänen P, Vainiola T, Sintonen H. Estimating the minimum important change in the 15D scores. Qual Life Res 2015; 24:599-606.

22. Li WWL, Lee TW, Lam SSY, et al. Quality of life following lung cancer resection: video-assisted thoracic surgery vs thoracotomy. Chest 2002; 122:584-9.

23. Aoki T, Tsuchida M, Hashimoto T, Saito M, Koike T, Hayashi J. Quality of life after lung cancer surgery: video-assisted thoracic surgery versus thoracotomy. Heart Lung Circ 2007; 16:285-9.

24. Kaseda S, Aoki T, Hangai N, Shimizu K. Better pulmonary function and prognosis with video-assisted thoracic surgery than with thoracotomy. Ann Thorac Surg 2000; 70:1644-6.

25. Balduyck B, Hendriks J, Sardari Nia P, Lauwers P, Van Schil P. Quality of life after lung cancer surgery: a review. Minerva Chir 2009; 64:655-63.

26. Win T, Sharples L, Wells FC, Ritchie AJ, Munday H, Laroche CM. Effect of lung cancer surgery on quality of life. Thorax 2005; 60:234-8.

27. Brunelli A, Socci L, Refai M, Salati M, Xiume F, Sabbatini A. Quality of life before and after major lung resection for lung cancer: a prospective follow-up analysis. Ann Thorac Surg 2007; 84:410-6.

28. Fortin M, Hudon C, Dubois M, Almirall J, Lapointe L, Soubhi H. Comparative assessment of three different indices of multimorbidity for studies on health-related quality of life. Health Qual Life Outcomes 2005; 3:74.

29. Wahlgren T, Levitt S, Kowalski J, Nilsson S, Brandberg Y. Use of the Charlson combined comorbidity index to predict postradiotherapy quality of life for prostate cancer patients. Int I Radiat Oncol Biol Phys 2011; 81:997-1004.

30. Ng X, Low AHL, Thumboo J. Comparison of the Charlson Comorbidity Index derived from self-report and medical record review in Asian patients with rheumatic diseases. Rheumatol Int 2015; 35:2005-11.

31. Kim S, Han H, Jung H, et al. Multidimensional frailty score for the prediction of postoperative mortality risk. JAMA Surg 2014; 149:633-40.

32. Travis WD, Travis LB, Devesa SS. Lung cancer. Cancer 1995; 75:191-202.

33. Gonzalez Saenz de Tejada M, Escobar A, Herrera C, Garcia L, Aizpuru F, Sarasqueta C. Patient expectations and health-related quality of life outcomes following total joint replacement. Value Health 2010; 13:447-54.

34. Wildgaard K, Ravn J, Nikolajsen L, Jakobsen E, Jensen TS, Kehlet H. Consequences of persistent pain after lung cancer surgery: a nationwide questionnaire study. Acta Anaesthesiol Scand 2011;55:60-8. 